Article

\title{
Sustainability \& CSR: The Relationship with Hofstede Cultural Dimensions
}

\author{
Minoo Tehrani ${ }^{1, *}$, Andreas Rathgeber ${ }^{2}$, Lawrence Fulton ${ }^{3}\left[\right.$ and Bryan Schmutz ${ }^{4}$ \\ 1 Gabelli School of Business, Roger Williams University, Bristol, RI 02809, USA \\ 2 Finance \& Information Management, Augsburg University, 86159 Augsburg, Germany; \\ andreas.rathgeber@mrm.uni-augsburg.de \\ 3 School of Health Administration, Texas State University, San Marcos, TX 78666, USA; larry.fulton@txstate.edu \\ 4 School of Business, Western New England University, Springfield, MA 01119, USA; bryan.schmutz@wne.edu \\ * Correspondence: mtehrani@rwu.edu
}

Citation: Tehrani, M.; Rathgeber, A.; Fulton, L.; Schmutz, B. Sustainability \& CSR: The Relationship with Hofstede Cultural Dimensions. Sustainability 2021, 13, 12052. https://doi.org/10.3390/su132112052

Academic Editor: Andrea Pérez

Received: 2 October 2021

Accepted: 25 October 2021

Published: 1 November 2021

Publisher's Note: MDPI stays neutral with regard to jurisdictional claims in published maps and institutional affiliations.

Copyright: () 2021 by the authors. Licensee MDPI, Basel, Switzerland. This article is an open access article distributed under the terms and conditions of the Creative Commons Attribution (CC BY) license (https:// creativecommons.org/licenses/by/ $4.0 /)$.

\begin{abstract}
This research explores the relationship between Hofstede's femininity cultural dimension of quality of life and the masculinity cultural dimension of drive for success manifested by materialistic wealth by investigating the market value of the publicly traded firms appearing on the Dow Jones Sustainability Indices (DJSIs). The firms added to the DJSIs between the years 2010-2019 in countries with the femininity cultural dimension indicated by scores of $\leq 42$, were selected for the first part of this study. In addition, France, with a masculinity score of 43 and Japan, with the highest masculinity score of 92, were chosen for comparison with the results from the countries with the femininity cultural dimension. The findings of this study indicate that companies in developed and emerging countries with the femininity cultural dimension show significant positive impact on their market values when added to the DJSIs. The publicly traded firms in France show a significant negative impact on their market values when added to the DJSIs. On the other hand, Japanese companies on the addition lists of DJSIs show a significant positive impact on their market values, despite Japan having the highest Hofstede masculinity score, a potential sign of cultural change in Japan.
\end{abstract}

Keywords: sustainability; CSR; DJSIs firm's market value; Hofstede's cultural dimensions; event study

\section{Introduction}

Numerous studies have utilized Hofstede's cultural dimensions [1,2] to examine different nations [3-7]. These studies have investigated different aspects of Hofstede's cultural dimensions, such as the individualistic versus collectivist dimensions $[4,7]$, and uncertainty avoidance [8]. Meanwhile, other studies [9] have researched the relationship between culture, corporate social responsibility (CSR), and impact on a firm's performance.

Investigating the relationship between the impact on the market values of the firms that adopt sustainability strategies to achieve a net-zero carbon emission economy and enhancing the health and the welfare of communities has been the focus of several studies [10-15]. The Dow Jones sustainability indices (DJSIs) that report the engagement of corporations in sustainability practices along the social, economic, and environmental dimensions started more than twenty years ago. These indices have been used in different studies to explore the extent of engagement in socially responsible sustainability practices [16-19]. Our research is novel in this area by utilizing Hofstede's femininity and masculinity cultural dimensions to explore the relationship between the market values of the publicly traded firms when adopting socially responsible sustainability strategies manifested by appearance on the Dow Jones Sustainability Indices. 


\section{Literature Review and Research Goals}

\subsection{Studies on Hofstede Cultural Dimensions}

Different studies have examined the relationship between culture and CSR [9] or the relationship between CSR among different groups of investors [18] and their impact on a firm's performance. According to Shi and Veenstra [9], there is a strong relationship between the cultural aspects of a country (e.g., individualism), CSR, and performance of the firms in that country [9]. The findings of their study indicate that in countries with Hofstede's collectivist cultural dimension, the shareholders value the engagement of the firms in socially responsible strategies indicated by positive impact on the financial performance of such companies. However, such an impact was not found in the countries that indicated Hofstede's individualistic cultural dimension [9].

Meanwhile, Lee et al. [18] studied different groups of investors and their reactions when the firms appeared on the DJSI in South Korea. The findings of their study indicate that governmental campaigns regarding CSR and appearance on the DSJI did not increase the market value of the firms [18].

This research explores the relationship between appearance of the firms on the DJSIs, the impact of the market value of the firms, and Hofstede's femininity and masculinity cultural dimensions. Based on Hofstede's cultural theories, countries with low masculinity scores of $\leq 42$ are considered cultures associated with attention to the quality of life [20]. The adoption of sustainability strategies by different companies can enhance the health and the welfare and subsequently the quality of life in the communities around them. As a result, firms that adopt socially responsible strategies and contribute to enhancing the quality of life, as demonstrated by appearing on the Dow Jones Sustainability Indices, should be rewarded by increased stock prices upon the release of such news in the countries with the femininity cultural dimension.

On the other hand, in the countries with masculinity scores of 43 and above, materialistic wealth is appreciated [20]. According to research exploring the relationship between the appearance of the firms on the DJSIs and the market value of such firms, investors may perceive the implementation of sustainability strategies to be costly to these companies $[14,21]$. Consequently, companies in countries with the masculinity cultural dimension and appreciation for materialistic wealth [22] should experience negative impacts on their market value when added to the DJSIs due to the stockholders' assumption that such strategies would be costly to the firm.

\subsection{Research Goals}

To investigate the relationship between the appearance of firms on the DJSIs and market value, this research selected companies that were added to the DJSIs between the years 2010 to 2019 in countries with Hofstede's masculinity scores of $\leq 42$, indicative of the femininity cultural dimension. The first proposal to be examined is delineated below:

1. There is a significant positive relationship between the market value of publicly traded companies and appearance on the DJSIs in countries characterized with the femininity cultural dimension (Hofstede's masculinity score of $\leq 42$ ).

This study investigated this proposal by examining the list of countries with the femininity cultural dimension whose companies have been added to the Dow Jones Sustainability Indices between the years 2010-2019 include European and also emerging countries.

The second proposal of this research considers the strict sustainability rules and regulations delineated by Paris Accord [23] and the European Union's net-zero carbon emission goals [24]. As a result, the second proposal compares the addition of the European publicly traded firms to the DJSIs and the impact on their market values versus other listed companies from emerging countries. This proposal is presented below:

2. Publicly traded companies added to the DJSIs between the years 2010-2019 from the corresponding European countries with the femininity cultural dimension are 
expected to see a higher significant positive impact on their market value compared to listed companies from the corresponding emerging countries.

To further explore the differences between countries with the femininity cultural dimension and the countries with the masculinity cultural dimension, firms in two more countries were added to this research, France and Japan. France, with a masculinity score of 43 , is considered halfway between the masculinity and femininity cultural dimensions. Japan, with the highest masculinity score of 92 is assumed to have the highest appreciation for material wealth. The proposals to be explored in this part of the research include:

3. There is a mixed significant negative or positive relationship between the market value of publicly traded French companies and their appearance on the DJSIs in France, a country with a Hofstede's masculinity score of 43, halfway between the femininity and masculinity cultural dimensions.

4. There is a significant negative relationship between the market value of publicly traded Japanese companies and appearance on the DJSIs in Japan, a country with the highest Hofstede's masculinity score of 92.

\section{Methodology}

\subsection{Selected Countries}

Hofstede Insights web site [25] was used to identify countries with a masculinity score of 42 and below, which comprise the countries with the femininity cultural dimension. During the years 2010-2019, the Dow Jones Sustainability Indices for the World, Europe, Asia Pacific, Korea, Emerging Markets, and MILA (Mercado Integrado Latinamericano) Pacific Alliance, were used to identify the companies that appeared on these lists in countries with the masculinity score of $\leq 42$. As a result, we identified ten countries. Table 1 presents the list of these countries.

Table 1. Countries with masculinity score of $\leq 42$, indicating femininity cultural dimension, 2010-2019.

\begin{tabular}{cc}
\hline Country & Masculinity Cultural Score \\
\hline Sweden & 5 \\
Norway & 8 \\
The Netherlands & 14 \\
Denmark & 16 \\
Finland & 26 \\
Chile & 28 \\
Portugal & 31 \\
Thailand & 34 \\
South Korea & 39 \\
Spain & 42 \\
\hline
\end{tabular}

As indicated in Table 1, there are ten countries on the DJSIs that fit the definition of countries with the femininity cultural dimension. Seven of these countries are located in Europe, with the northern European countries indicating the lowest masculinity scores (5-26). Portugal (31) and Spain (42) are the other European countries on the list. All the European countries on the above list have signed the Paris Accord and, with the exception of Norway, all of them are members of the European Union. The rest of the countries on this list are from Latin America and Asia and are considered emerging countries. They include Chile (28), South Korea (39), and Thailand (34).

Table 2 presents the companies in the European countries on Table 1 that appeared on the DJSI World and DJSI Europe during the years 2010-2019. 
Table 2. List of the companies on the Dow Jones Sustainability addition lists and their corresponding European countries with the femininity cultural dimension (scores of $\leq 42$ ), 2010-2019.

\begin{tabular}{cccc}
\hline e & Index & Company & Country \\
\hline 2010 & DJSI World & Aegon N.V. & The Netherlands \\
2010 & DJSI Europe & Aegon N.V. & The Netherlands \\
2010 & DJSI Europe & Royal KPN N.V. & The Netherlands \\
2010 & DJSI Europe & Portugal Telecom SGPS S/A & Portugal \\
2010 & DJSI World & Gamesa Corporacion Tecnologica S.A. & Spain \\
2010 & DJSI World & Red Electrica Corp. S.A & Spain \\
2011 & DJSI Europe & Orkla ASA & Norway \\
2011 & DJSI Europe & Atlas Copco AB & Sweden \\
2011 & DJSI Europe & Svenska Cellulosa AB & Sweden \\
2012 & DJSI Europe & UPM-Kymmene OYJ & Finland \\
2012 & DJSI Europe & Aegon NV & The Netherlands \\
2012 & DJSI Europe & Koninklijke Ahold NV & The Netherlands \\
2012 & DJSI Europe & Telenor ASA & Norway \\
2012 & DJSI Europe & Amadeus IT Holding SA & Spain \\
2012 & DJSI World & Hennes \& Mauritz AB & Sweden \\
2013 & DJSI World & ING Groep NV & The Netherlands \\
2013 & DJSI Europe & ASML Holding NV & The Netherlands \\
2013 & DJSI Europe & ING Groep NV & The Netherlands \\
2013 & DJSI World & Telefonica SA & Spain \\
2014 & DJSI World & Telefonica SA & Spain \\
2015 & DJSI World & Telefonica SA & Spain \\
2016 & DJSI Europe & Novo Nordisk A/S & Denmark \\
2016 & DJSI Europe & Iberdrola SA & Spain \\
2017 & DJSI World & ASML Holding NV & The Netherlands \\
2018 & DJSI World & Banco Bilbao Vizcaya Argentaria SA & Spain \\
2018 & DJSI Europe & Banco Bilbao Vizcaya Argentaria SA & Spain \\
2018 & DJSI Europe & Essity AB & Sweden \\
2019 & DJSI Europe & Telfonaktiebolaget LM Ericsson & Sweden \\
\hline & & & \\
\hline
\end{tabular}

Table 3 presents the list of the companies from the emerging countries with the femininity cultural dimension (scores of $\leq 42$ ) on the Dow Jones Sustainability addition lists during the years 2010-2019. The indices included DJSI World, DJSI Korea, DJSI Asia Pacific, DJSI MILA Pacific Alliance, and DJSI Emerging Markets.

Table 4 presents the French companies on the Dow Jones Sustainability addition lists collected from DJSI Europe and DJSI World during the years 2010-2019.

Table 5 presents the Japanese companies on the Dow Jones Sustainability lists, DJSI World, and DJSI Asia Pacific, during the years 2010-2019. 
Table 3. The list of the companies on the Dow Jones Sustainability addition lists and their associated emerging countries with the femininity cultural dimension (scores of $\leq 42$ ), 2010-2019.

\begin{tabular}{lccc}
\hline Year & Index & Company & Country \\
\hline 2010 & DJSI World & KT\&G Corp. & S. Korea \\
2011 & DJSI World & Hyundai Mobis Co. Ltd. & S. Korea \\
2011 & DJSI Korea & Hynix Semiconductor Inc. & S. Korea \\
2011 & DJSI Korea & Samsung Engineering Co. Ltd. & S. Korea \\
2011 & DJSI Korea & Samsung Heavy Industries Co. Ltd. & S. Korea \\
2012 & DJSI Korea & Hanjin Shipping Co Ltd. & S. Korea \\
2012 & DJSI Korea & KCC Corp. & S. Korea \\
2012 & DJSI Korea & Samsung Life Insurance Co Ltd. & S. Korea \\
2012 & DJSI Asia Pacific & Samsung Life Insurance Co Ltd. & S. Korea \\
2013 & DJSI World & Shinhan Financial Group Co Ltd. & S. Korea \\
2013 & DJSI Korea & Hanwha Chemical Corp. & S. Korea \\
2013 & DJSI Korea & LG Household \& Health Care Ltd. & S. Korea \\
2013 & DJSI Korea & Samsung C\&T Corp. & S. Korea \\
2013 & DJSI Asia Pacific & Samsung Fire \& marine Insurance Co Ltd. & S. Korea \\
2015 & DJSI Emerging Markets & SACI Falabella & Chile \\
2015 & DJSI Emerging Markets & Advanced Info Service PCL & Thailand \\
2016 & DJSI Emerging Markets & Kasikornbank PCL & Thailand \\
2016 & DJSI Emerging Markets & Thai Beverage PCL & Thailand \\
2017 & DJSI World & Samsung Electronics Co Ltd. & S. Korea \\
2017 & DJSI Asia Pacific & Samsung Electronics Co Ltd. & S. Korea \\
2017 & DJSI Emerging Markets & CP ALL PCL & Thailand \\
2018 & DJSI MILA Pacific Alliance & Enel Americas SA & Chile \\
2018 & DJSI MILA Pacific Alliance & Enel Chile SA & Chile \\
2018 & DJSI MILA Pacific Alliance & Inversiones La Construccion SA & Chile \\
2018 & DJSI Emerging Markets & Enel Americas SA & Chile \\
\hline
\end{tabular}

Table 4. French companies on the Dow Jones Sustainability addition lists, 2010-2019.

\begin{tabular}{lccc}
\hline Year. & Index & Company & Country \\
\hline 2010 & DJSI Europe & Klepierre S.A. & France \\
2011 & DJSI World & Schneider Electric S.A & France \\
2011 & DJSI World & Societe Generale S.A & France \\
2011 & DJSI Europe & Alcatel-Lucent & France \\
2011 & DJSI Europe & Alstom S.A & France \\
2011 & DJSI Europe & Societe Generale S.A. & France \\
2013 & DJSI Europe & Kering & France \\
2013 & DJSI Europe & LVMH-Moët Hennessy Louis Vuitton SA & France \\
2013 & DJSI Europe & Societe Generale SA & France \\
2015 & DJSI World & GDF Suez & France \\
2015 & DJSI World & Societe Generale SA & France \\
2015 & DJSI World & Vinci SA & France \\
2015 & DJSI Europe & BNP Paribas SA & France \\
2015 & DJSI Europe & Sanofi & France \\
2015 & DJSI Europe & Societe Generale SA & France \\
2016 & DJSI World & Essilor International SA & France \\
2016 & DJSI Europe & Essilor International SA & France \\
2016 & DJSI Europe & TOTAL SA & France \\
2017 & DJSI Europe & CapgeminiSA & France \\
2019 & DJSI Europe & BNP Paribas SA & France \\
2019 & DJSI Europe & Sanofi & France \\
\hline
\end{tabular}


Table 5. Japanese companies on the Dow Jones Sustainability addition lists, 2010-2019.

\begin{tabular}{|c|c|c|c|}
\hline Year & Index & Company & Country \\
\hline 2010 & DJSI World & Nippon Yusen K.K & Japan \\
\hline 2010 & DJSI Asia Pacific & Seiko Epson Corp. & Japan \\
\hline 2010 & DJSI Asia Pacific & Yokogawa Electric Corp. & Japan \\
\hline 2011 & DJSI Asia Pacific & Asahi Glass Co. Ltd. & Japan \\
\hline 2011 & DJSI Asia Pacific & Astellas Pharma Inc. & Japan \\
\hline 2011 & DJSI Asia Pacific & Itochu Corp. & Japan \\
\hline 2011 & DJSI Asia Pacific & Mitsubishi Corp. & Japan \\
\hline 2011 & DJSI Asia Pacific & Mitsubishi Estate Co. Ltd. & Japan \\
\hline 2011 & DJSI Asia Pacific & Mitsubishi UFJ Financial Group Inc. & Japan \\
\hline 2011 & DJSI Asia Pacific & NTT DoCoMo Inc. & Japan \\
\hline 2011 & DJSI Asia Pacific & Sumitomo Mitsui Trust Holdings Inc. & Japan \\
\hline 2012 & DJSI Asia Pacific & JSR Corp. & Japan \\
\hline 2012 & DJSI Asia Pacific & Kirin Holdings Co Ltd. & Japan \\
\hline 2012 & DJSI Asia Pacific & Nitto Denko Corp. & Japan \\
\hline 2012 & DJSI Asia Pacific & Sysmex Corp. & Japan \\
\hline 2012 & DJSI Asia Pacific & Tokyu Land Corp. & Japan \\
\hline 2013 & DJSI World & ITOCHU Corp. & Japan \\
\hline 2013 & DJSI Asia/Pacific & Daiwa House Industry Co Ltd. & Japan \\
\hline 2013 & DJSI Asia/Pacific & Eisai Co Ltd. & Japan \\
\hline 2013 & DJSI Asia/Pacific & Inpex Corp. & Japan \\
\hline 2013 & DJSI Asia/Pacific & ITOCHU Corp. & Japan \\
\hline 2013 & DJSI Asia/Pacific & Sumitomo Electric Industries Ltd. & Japan \\
\hline 2015 & DJSI World & Mitsubishi Corp. & Japan \\
\hline 2015 & DJSI World & Nomura Holdings Inc. & Japan \\
\hline 2015 & DJSI Asia Pacific & Honda Motor Co Ltd. & Japan \\
\hline 2015 & DJSI Asia Pacific & Mizuho Financial Group & Japan \\
\hline 2015 & DJSI Asia Pacific & Terumo Corp. & Japan \\
\hline 2016 & DJSI World & Bridgestone Corp. & Japan \\
\hline 2016 & DJSI World & Nissan Motor Co Ltd. & Japan \\
\hline 2016 & DJSI Asia Pacific & Fast Retailing Co Ltd. & Japan \\
\hline 2016 & DJSI Asia Pacific & Mitsui \& Co Ltd. & Japan \\
\hline 2016 & DJSI Asia Pacific & MS\&AD Insurance Group Japan Holdings Inc. & Japan \\
\hline 2016 & DJSI Asia Pacific & NTT DOCOMO Inc. & Japan \\
\hline 2016 & DJSI Asia Pacific & Tokyo Electron Ltd. & Japan \\
\hline 2017 & DJSI World & Honda Motor Co Ltd. & Japan \\
\hline 2017 & DJSI World & NTT Docomo Inc. & Japan \\
\hline 2017 & DJSI Asia Pacific & Kubota Corp. & Japan \\
\hline 2017 & DJSI Asia Pacific & Mitsubishi Heavy Industries Ltd. & Japan \\
\hline 2017 & DJSI Asia Pacific & Sekisui House Ltd. & Japan \\
\hline 2018 & DJSI World & Nippon Telegraph \& Telephone Corp. & Japan \\
\hline 2018 & DJSI Asia Pacific & Chugai Pharmaceutical Co Ltd. & Japan \\
\hline 2018 & DJSI Asia Pacific & Ricoh Co Ltd. & Japan \\
\hline 2018 & DJSI Asia Pacific & Tokio Marine Holdings Inc. & Japan \\
\hline 2019 & DJSI World & Takeda Pharmaceutical Co Ltd. & Japan \\
\hline 2019 & DJSI Asia Pacific & Eisai Co Ltd. & Japan \\
\hline 2019 & DJSI Asia Pacific & Meiji Holdings Co Ltd. & Japan \\
\hline 2019 & DJSI Asia Pacific & Olympus Corp. & Japan \\
\hline 2019 & DJSI Asia Pacific & Recruit Holdings Co Ltd. & Japan \\
\hline
\end{tabular}

\subsection{Statistical Analyses}

Studies on the information released in the capital markets and the impacts on the stock prices of the companies have often utilized event study methods [26-29]. According to these studies, a firm's value can be examined based on the new available information in the capital markets. Utilizing event study, one can investigate the impact on a firms' stock price of the release of such information within short windows of time [29]. As a result, event study can indicate the positive impact on the abnormal rate of returns (ARRs) when the released information is considered beneficial, or it can show negative abnormal rate 
of returns when the market assumes that the released information is harmful [30]. The market model is often utilized to estimate ARRs [31,32]. The market model allows for the calculation of the correlation between stock price and expected or normal return on or around a window of time when specific information (the event) is released to capital markets [31,32]. The market model uses a short window before the event and assesses the abnormal returns (AR) on the stock. In addition, a short window is used after the event to allow for the calculation of the abnormal rate of returns (ARRs), which is the return due to the new information about the company (i.e., event), the cumulative abnormal returns (CAR), and cumulative average abnormal returns (CAARs) [31,32].

This research utilizes event study to explore the impact of addition to the Dow Jones Sustainability Indices on the companies' stock prices in the European countries presented in Table 2 and in the emerging countries presented in Table 3. Since France is halfway between the femininity and masculinity cultural dimensions with a score of 43 , the French companies presented in Table 4 are also examined. Furthermore, the Japanese companies that were added to the DJSIs during the years 2010-2019 (Table 5) are also examined, and the results are compared with the companies in the countries with the femininity cultural dimension (Tables 2 and 3).

All stock prices of the companies under the study were taken from the corresponding country's stock market exchanges and currency within the years 2010-2019. The stock market exchanges for collecting the European stock prices included DJSI World and DJSI Europe. The currencies for the European countries included Norwegian Krone, Danish Krone, Swedish Krona, and for the rest, Euro. For South Korea, the currency used for the statistical analyses was the Won, and for Chile, the Chilean Peso. This information was collected from the corresponding stock market exchanges: DJSI Korea, DJSI Asia Pacific, DJSI MILA Pacific Alliance, DJSI World, and DJSI Emerging Markets. For Thailand, we had to use the Singapore dollar for one company (Thai Beverage), but the rest of the Thai companies' stock prices were evaluated with Thai Baht. For France, DJSI World and DJSI Europe with Euro as the currency comprised the data. For Japan, DJSI World and DJSI Asia Pacific were used to collect the data with Japanese Yen as the currency.

\section{Results}

In order to investigate the impact of the addition to the DJSI lists for the countries with the femininity cultural dimensions, event study was utilized. Stock prices, within windows starting at most 10 days before and ending at most 10 days after the event, were investigated to evaluate the cumulative abnormal returns (CARs) for firms in the countries with Hofstede masculinity score of $\leq 42$. Table 6 and Figure 1 present the results of this part of the study.

Table 6. Daily cumulative abnormal returns (CARs) around the announcement dates for companies added to the DJSI in countries with Hofstede masculinity scores of $\leq 42,2010-2019$.

\begin{tabular}{cccc}
\hline \multicolumn{2}{c}{ Additions to the DJSIs 2010-2019 } \\
N $=49$ & CAR \\
Day & CAR & Day & 0.0268 \\
-10 & -0.0003 & 1 & 0.0316 \\
-9 & 0.0083 & 2 & 0.0434 \\
-8 & 0.0098 & 3 & 0.0455 \\
-7 & 0.0170 & 4 & 0.0428 \\
-6 & 0.0211 & 5 & 0.0394 \\
-5 & 0.0206 & 6 & 0.0394 \\
-4 & 0.0111 & 7 & 0.0246 \\
-3 & 0.0076 & 8 & 0.0137 \\
-2 & 0.0188 & 9 & 0.0148 \\
\hline
\end{tabular}




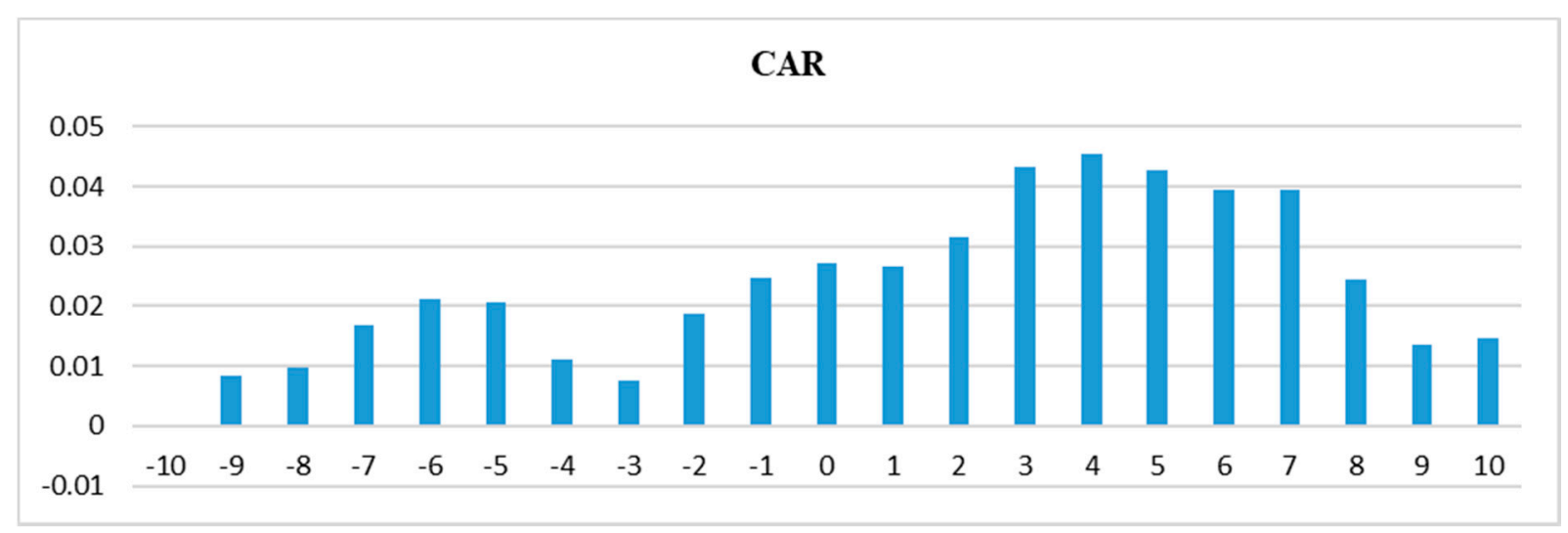

Figure 1. Daily cumulative abnormal returns (CARs) around the announcement date $[-10,10]$ for the companies added to the DJSIs for countries with Hofstede masculinity scores of $\leq 42$.

As presented in Table 6 and Figure 1, the event study using a symmetric 10-day event window $[-10,10]$ shows that addition to the DJSIs result in a positive impact on the cumulative abnormal returns (CARs) after the announcement for the companies in countries with the femininity cultural dimension. As indicated in Table 6 and Figure 1, this impact is more pronounced from 1-7 days after the announcement date.

In the event study, CAARs were compared to the expected market model and then evaluated for statistically significant indicators. Simple t-tests were conducted to evaluate the significance of the findings. Table 7 is the event study analysis for four different windows: $[-10,10],[-2,2],[-5,5]$, and $[-1,1]$.

Table 7. Cumulative average abnormal returns (CAARs) around the announcement date [-10, 10] for the companies added $(\mathrm{N}=49)$ to the DJSIs in the countries with femininity cultural dimension, Hofstede's score of $\leq 42,2010-2019$.

\begin{tabular}{ccc}
\hline Days & CAAR & $\begin{array}{c}\mathbf{t} \text {-Test } \\
\boldsymbol{p} \text {-Value }\end{array}$ \\
\hline$[-10,10]$ & $1.48 \%^{* * *}$ & 0.1974 \\
{$[-2,2]$} & $2.40 \%^{* * *}$ & $\mathbf{0 . 0 0 3 1}$ \\
{$[-5,5]$} & $2.16 \%^{* * *}$ & $\mathbf{0 . 0 4 4 5}$ \\
{$[-1,1]$} & $0.799 \%$ & 0.1129 \\
\hline Note: Significant differences have been bolded.** $p<0.0$ ( $^{* * *} p<0.001$
\end{tabular}

Note: Significant differences have been bolded. ${ }^{* *}, p<0.01,{ }^{* * *}, p<0.001$.

As indicated in Table 7, the announcement of the addition to the DJSIs has a significant positive impact on the cumulative average abnormal returns (CAARs) of the companies in countries with femininity cultural dimension for $[-2,2]$ and $[-5,5]$ windows.

The results of this part of the research indicate support for Proposal 1 of this study. There was a significant positive relationship between the market values of the publicly traded companies and their appearance on the Dow Jones Sustainability Indices in the countries characterized with the femininity cultural dimension by having the masculinity score of $\leq 42$. Based on these results, there was a significant increase in the stock prices of the companies when they were added to the Dow Jones Sustainability Indices in the countries with femininity cultural dimension. These results provide further support for Hofstede's concept that the countries with low masculinity scores value quality of life that is manifested in this study by rewarding the companies that adopt socially responsible strategies with the potential of enhancing the health and the welfare of the communities.

In the following event study analysis, the impact of the addition of the companies to the DJSIs on the cumulative abnormal returns (CARs) for the developed countries (The Netherlands, Spain, Sweden, Norway, Denmark, Finland) were compared with those in emerging countries (South Korea, Chile, Thailand). Tables 8 and 9 and Figures 2 and 3 
present the results of this part of the study. There was only one company from Portugal during the years 2010-2019 that was added to the DJSI, but the company was privately held and thus excluded from further analysis.

Table 8. Daily cumulative abnormal returns (CARs) around the announcement date $[-10,10]$ for the companies added to the DJSIs in the developed countries with Hofstede's masculinity score of $\leq 42$, 2010-2019.

\begin{tabular}{cccc}
\hline \multicolumn{5}{c}{ Additions to the DJSIs, 2010-2019-Developed Countries } \\
$\mathbf{N = 2 4}$ \\
\hline Day & CAR & Day & CAR \\
-10 & -0.0012 & 1 & 0.0347 \\
-9 & 0.0081 & 2 & 0.0395 \\
-8 & 0.0070 & 3 & 0.0487 \\
-7 & 0.0256 & 4 & 0.0578 \\
-6 & 0.0339 & 5 & 0.0537 \\
-5 & 0.0304 & 6 & 0.0453 \\
-4 & 0.0233 & 7 & 0.0539 \\
-3 & 0.0212 & 8 & 0.0106 \\
-2 & 0.0286 & 9 & 0.0044 \\
-1 & 0.0355 & 10 & 0.0143 \\
0 & 0.0331 & & \\
\hline
\end{tabular}

Table 9. Daily cumulative abnormal returns (CARs) around the announcement date $[-10,10]$ for companies added to the DJSIs in the emerging countries with Hofstede's masculinity score of $\leq 42$, 2010-2019.

\begin{tabular}{cccc}
\hline \multicolumn{5}{c}{ Additions to the DJSIs, 2010-2019-Emerging Countries } \\
$\mathbf{N}=\mathbf{2 5}$ & \\
\hline Day & CAR & Day & CAR \\
-10 & 0.0005 & 1 & 0.0193 \\
-9 & 0.0085 & 2 & 0.0241 \\
-8 & 0.0124 & 3 & 0.0384 \\
-7 & 0.0087 & 4 & 0.0337 \\
-6 & 0.0089 & 5 & 0.0323 \\
-5 & 0.0112 & 6 & 0.0337 \\
-4 & -0.0006 & 7 & 0.0255 \\
-3 & -0.0055 & 8 & 0.0106 \\
-2 & 0.0095 & 9 & 0.0044 \\
-1 & 0.0145 & 10 & 0.0143 \\
0 & 0.0214 & & \\
\hline
\end{tabular}

\section{CAR}

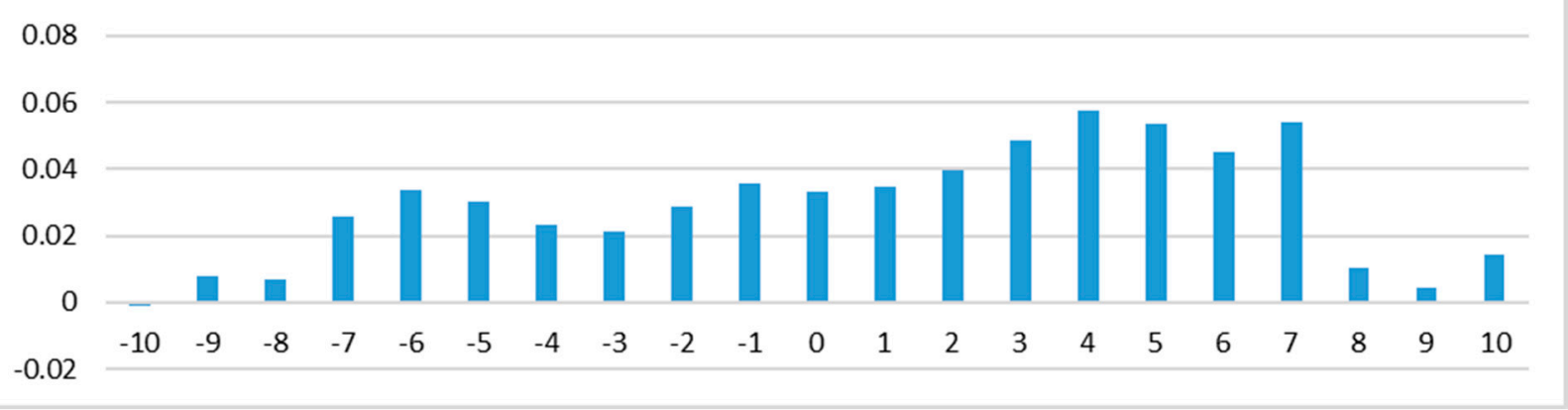

Figure 2. Daily cumulative abnormal returns (CARs) around the announcement date $[-10,10]$ for the companies added to the DJSI in the developed countries with Hofstede's masculinity score of $\leq 42,2010-2019$. 


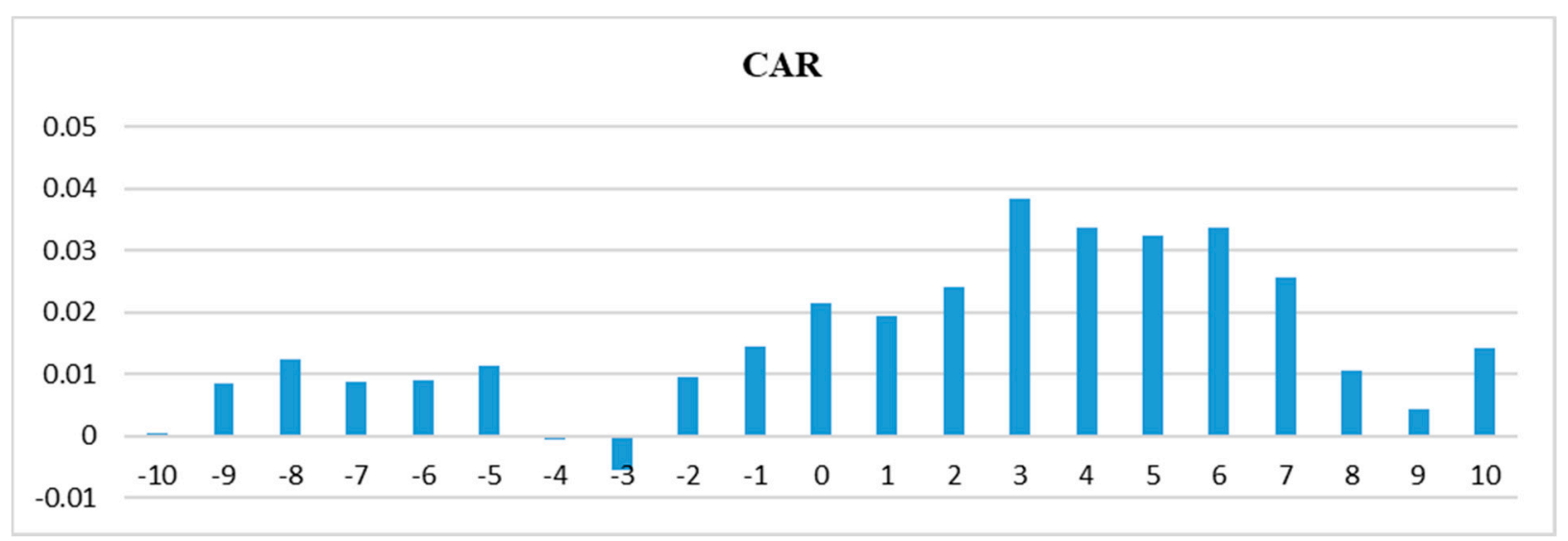

Figure 3. Daily cumulative abnormal returns (CARs) around the announcement date $[-10,10]$ for companies added to the DJSIs in the emerging countries with Hofstede's masculinity score of $\leq 42,2010-2019$.

As presented in Tables 8 and 9 and Figures 2 and 3, the event study using a symmetric 10-day event window $[-10,10]$ shows that addition to the DJSIs for the companies in developed countries with the femininity cultural dimension results in a positive impact on cumulative abnormal returns on day 1 after the announcement date. However, for companies added to the DJSIs in emerging countries with the femininity cultural dimension, this impact was more pronounced on day 2 after the announcement date. In both instances, the positive impact continued through day 7 after the announcement date.

To provide support for the results of the event study presented in Tables 8 and 9, a market model analysis was conducted. The results are presented in Tables 10 and 11.

Table 10. Cumulative average abnormal returns (CAARs) around the announcement date $[-10,10]$ for companies added $(\mathrm{N}=24)$ to the DJSIs in developed countries with Hofstede masculinity score of $\leq 42,2010-2019$.

\begin{tabular}{ccc}
\hline Event Window & CAAR & $\begin{array}{c}\text { t-Test } \\
p \text {-Value }\end{array}$ \\
\hline$[-10,10]$ & $1.534^{*}$ & 0.1214 \\
{$[-2,2]$} & $1.82 \%^{* *}$ & $\mathbf{0 . 0 0 3 8}$ \\
{$[-5,5]$} & $1.978 \%^{* *}$ & $\mathbf{0 . 0 2 1 7}$ \\
{$[-1,1]$} & $0.611 \%$ & 0.1095 \\
\hline
\end{tabular}

Note: Significant differences have been bolded. ${ }^{* *}, p<0.01$.

Table 11. Cumulative average abnormal returns (CAARs) around the announcement date $[-10,10]$ for companies added $(\mathrm{N}=25)$ to the DJSIs in emerging countries with Hofstede masculinity scores of $\leq 42,2010-2019$.

\begin{tabular}{ccc}
\hline Event Window & CAAR & $\begin{array}{c}\text { t-Test } \\
p \text {-Value }\end{array}$ \\
\hline$[-10,10]$ & $1.429 \%$ & 0.3270 \\
{$[-2,2]$} & $2.959 \% * *$ & $\mathbf{0 . 0 3 3 0}$ \\
{$[-5,5]$} & $2.346 \%$ & 0.1567 \\
{$[-1,1]$} & $0.980 \%$ & 0.2091 \\
\hline
\end{tabular}

Note: Significant differences have been bolded. ${ }^{* *}, p<0.01$.

As indicated in Table 10, the results of the model market study for companies added to the DJSIs in the developed countries support the event study results shown in Table 8 . The announcement of addition to the DJSIs has a significant positive impact on the cumulative abnormal returns of companies (CAARs) in the developed countries with masculinity score of $\leq 42$ for the windows $[-2,2]$ and $[-5,5]$ as indicated by $\left(^{* *}\right)$ in Table 10 . However, as presented in Table 11, the results of the market model analysis for the companies added 
to the DJSIs in emerging countries indicate that addition to the DJSIs creates a significant positive impact on the cumulative average abnormal return for a shorter period of time of up to 2 days after the announcement date as indicated by (**). Proposal 2 of this study investigated if the studied firms in European countries with the femininity cultural dimension would show a higher significant positive impact on their market values than the listed companies from corresponding emerging countries. The results of this part of the study indicate that the companies on the Dow Jones Sustainability Indices from the listed developed countries show a significant positive impact on their market values when they appear on the DJSIs. The companies on the DJSIs from the listed emerging countries also show a significant positive impact on their market values, but for a shorter period of time. Again, these results provide support for Hofstede's concept regarding countries with the femininity cultural dimension appreciating quality of life. Based on the above results, stockholders in such countries appear to reward the adoption of socially responsible practices by their home companies that have the potential of enhancing quality of life, as indicated by higher stock prices when added to the DJSIs.

The next part of the study concentrates on Proposal 3 to investigate if there is a mixed significant negative or positive relationship between the market value of publicly traded French companies and appearance on the DJSIs in France. France, with its Hofstede's masculinity score of 43 , is considered halfway between the femininity and masculinity cultural dimensions. Table 12 and Figure 4 present the daily cumulative abnormal returns (CARs) for French companies that were added to the Dow Jones Sustainability Indices during the years 2010-2019.

Table 12. Results of the daily abnormal returns around the announcement date $[-10,10]$ for the French companies added to the Dow Jones Sustainability Indices, 2010-2019.

\begin{tabular}{|c|c|c|c|}
\hline \multicolumn{4}{|c|}{$\begin{array}{l}\text { Additions to the DJSIs, 2010-2019-French Companies } \\
\qquad N=14\end{array}$} \\
\hline Day & CAR & Day & CAR \\
\hline-10 & -0.0281 & 1 & -0.0430 \\
\hline-9 & -0.0094 & 2 & -0.0272 \\
\hline-8 & 0.0089 & 3 & -0.0309 \\
\hline-7 & 0.0248 & 4 & -0.0010 \\
\hline-6 & 0.0348 & 5 & -0.0193 \\
\hline-5 & 0.0284 & 6 & -0.0372 \\
\hline-4 & 0.0054 & 7 & -0.0385 \\
\hline-3 & -0.0135 & 8 & -0.0337 \\
\hline-2 & -0.0078 & 9 & -0.0900 \\
\hline-1 & -0.0061 & 10 & -0.0959 \\
\hline 0 & -0.0265 & & \\
\hline
\end{tabular}

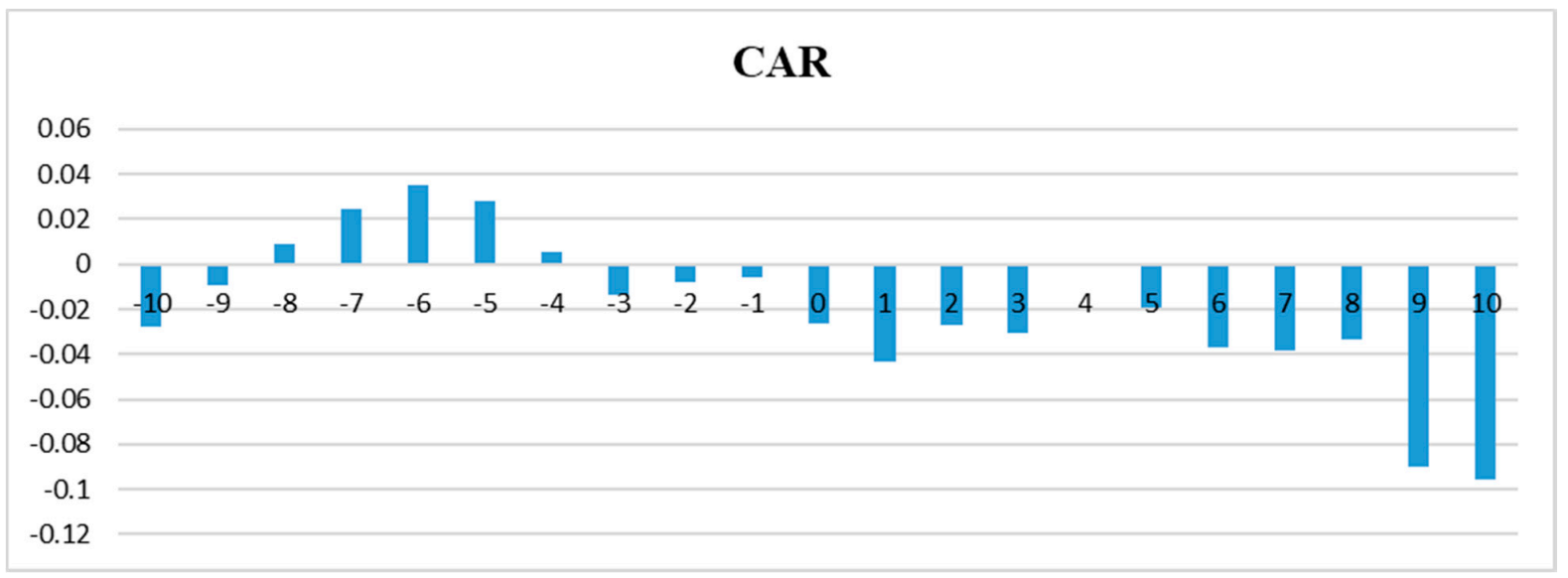

Figure 4. Results of the daily abnormal returns around the announcement date $[-10,10]$ for the French companies added to the Dow Jones Sustainability Indices, 2010-2019. 
As indicated in Table 12 and Figure 4, the daily cumulative abnormal returns (CARs) indicate that the French companies that are added to the Dow Jones Sustainability Indices experience negative impacts on their stock prices. In order to strengthen the above findings, market model analysis was also conducted on these data. Table 13 indicates the results of this part of the research.

Table 13. Cumulative average abnormal returns (CAARs) around the announcement date $[-10,10]$ for the French companies added ( $\mathrm{N}=14$ ) to the DJSIs, 2010-2019.

\begin{tabular}{ccc}
\hline Event Window & CAAR & $\begin{array}{c}\text { t-Test } \\
p \text {-Value }\end{array}$ \\
\hline$[-10,10]$ & $-9.589^{* * *}$ & $\mathbf{0 . 0 0 0 1}$ \\
{$[-2,2]$} & $-1.36 \%^{*}$ & $\mathbf{0 . 0 8 1 8}$ \\
{$[-5,5]$} & $-5.41 \%^{* * *}$ & $\mathbf{0 . 0 0 0 8}$ \\
{$[-1,1]$} & $-3.52 \%^{* * *}$ & $\mathbf{0 . 0 0 0 1}$ \\
\hline
\end{tabular}

Note: Significant differences have been bolded. ${ }^{*}, p<0.05,{ }^{* * *}, p<0.001$.

As presented in Table 13, the results of the model market analysis for the French companies that were added to the Dow Jones Sustainability Indices during the years 2010-2019 show a prolonged significant negative impact on their market value within the $[-1,1]$ to $[-10,10]$ windows indicated by $\left({ }^{*}, * * *\right)$.

Proposal 3 of this study was to explore the notion that France, being half-way between the femininity and masculinity cultural dimensions with a score of 43 , shows a mixed reaction to companies that adopt the sustainability practices. However, the results of the statistical analyses do not support this proposal. The appearance of the French companies on the Dow Jones Sustainability Indices shows a significant negative and prolonged impact on the market value of such firms. These results are interesting, considering that France is a member of the European Union and it is where the Paris Accord was signed.

The following part of the study concentrated on the Japanese companies and Proposal 4 of this research. This proposal investigated whether there was a significant negative relationship between the market value of the publicly traded Japanese companies and appearance on the DJSIs in Japan, with the highest Hofstede's masculinity score of 92. Table 14 shows the results of the event study for the daily cumulative abnormal returns (CARs) for the Japanese companies that were added to the Dow Jones Sustainability Indices from 2010 through 2019.

Table 14. Results of the daily abnormal returns around the announcement date [-10,10] for Japanese companies added to the Dow Jones Sustainability Indices, 2010-2019.

\begin{tabular}{cccc}
\hline \multicolumn{5}{c}{ Additions to the DJSIs, 2010-2019-Japanese Companies } \\
$\mathbf{N = 4 9}$ & CAR \\
Day & CAR & Day & 0.0241 \\
-10 & -0.0116 & 1 & 0.0295 \\
-9 & -0.0063 & 2 & 0.0273 \\
-8 & 0.0049 & 3 & 0.0312 \\
-7 & 0.0087 & 4 & 0.0521 \\
-6 & 0.0149 & 5 & 0.0474 \\
-5 & 0.0144 & 6 & 0.0329 \\
-4 & 0.0249 & 7 & 0.0356 \\
-3 & 0.0185 & 8 & 0.0252 \\
-2 & 0.0203 & 9 & 0.0332 \\
-1 & 0.0230 & 10 & \\
\hline 0 & 0.0264 & & \\
\hline
\end{tabular}

As indicated in Table 14 and Figure 5, Japanese companies show positive impacts on their market value when added to the Dow Jones Sustainability Indices. To further 
investigate these results, a market model analysis was again conducted. The results are presented in Table 15.

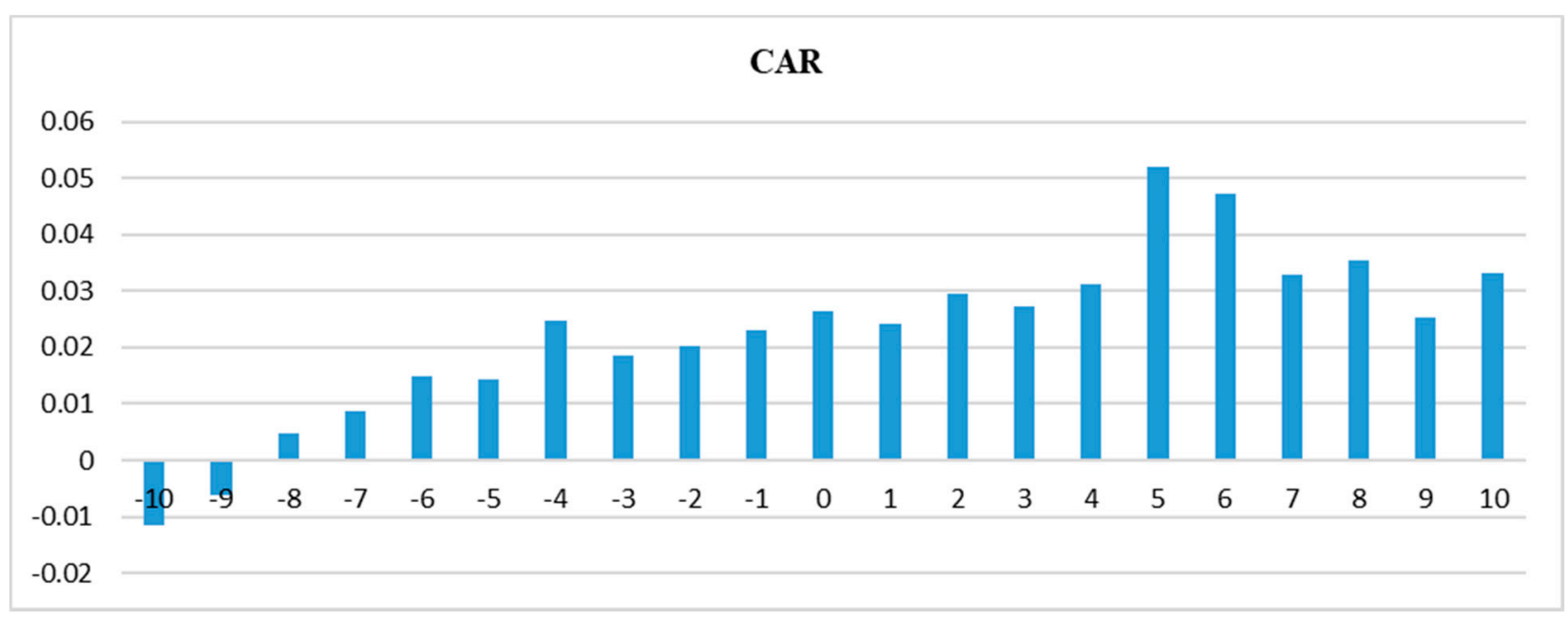

Figure 5. Results of the daily abnormal returns around the announcement date $[-10,10]$ for Japanese companies added to the Dow Jones Sustainability Indices, 2010-2019.

Table 15. Cumulative average abnormal returns (CAARs) around the announcement date $[-10,10]$ for Japanese companies added $(\mathrm{N}=49)$ to the DJSIs, 2010-2019.

\begin{tabular}{ccc}
\hline Event Window & CAAR & $\begin{array}{c}\text { t-Test } \\
p \text {-Value }\end{array}$ \\
\hline$[-10,10]$ & $3.32 \%^{* * * *}$ & $\mathbf{0 . 0 0 1 5}$ \\
{$[-2,2]$} & $1.10 \%^{* *}$ & $\mathbf{0 . 0 1 9 8}$ \\
{$[-5,5]$} & $3.71 \%^{* * *}$ & $\mathbf{0 . 0 0 0 0}$ \\
{$[-1,1]$} & $0.37 \%^{* * *} p<0.001$. & 0.1778 \\
\hline Note: Significant differences have been bolded. ${ }^{* *}, p<0.01{ }^{* * *}, p$
\end{tabular}

Note: Significant differences have been bolded. ${ }^{* *}, p<0.01,{ }^{* * *}, p<0.001$.

The results presented in Table 15 support the findings indicated in Table 14 and Figure 5. Japanese companies indicate higher and longer significant positive impacts on their market value when they are added to the Dow Jones Sustainability Indices, as indicated by $\left({ }^{*}, * *, * * *\right)$. The results of the above statistical analyses do not support Proposal 4 of this study. Japan, with the highest masculinity score of 92 should show a significant negative relationship between the market value of the publicly traded companies and appearance on the DJSIs. However, the results do not support such relationship. It is interesting to note that there are more Japanese companies (49) on the DJSI lists during the years 2010-2019 than any country with the femininity cultural dimension. In addition, the impact on the market value of the Japanese companies is significantly positive and more prolonged than in the other studied companies on the DJSI lists in the countries with the femininity cultural dimension.

To create a visualization of the findings of this study, we plotted the calculated CARs. These calculated CARs depict companies in the sample data in the European, emerging countries, France, and Japan. Figure 6 shows the results. 


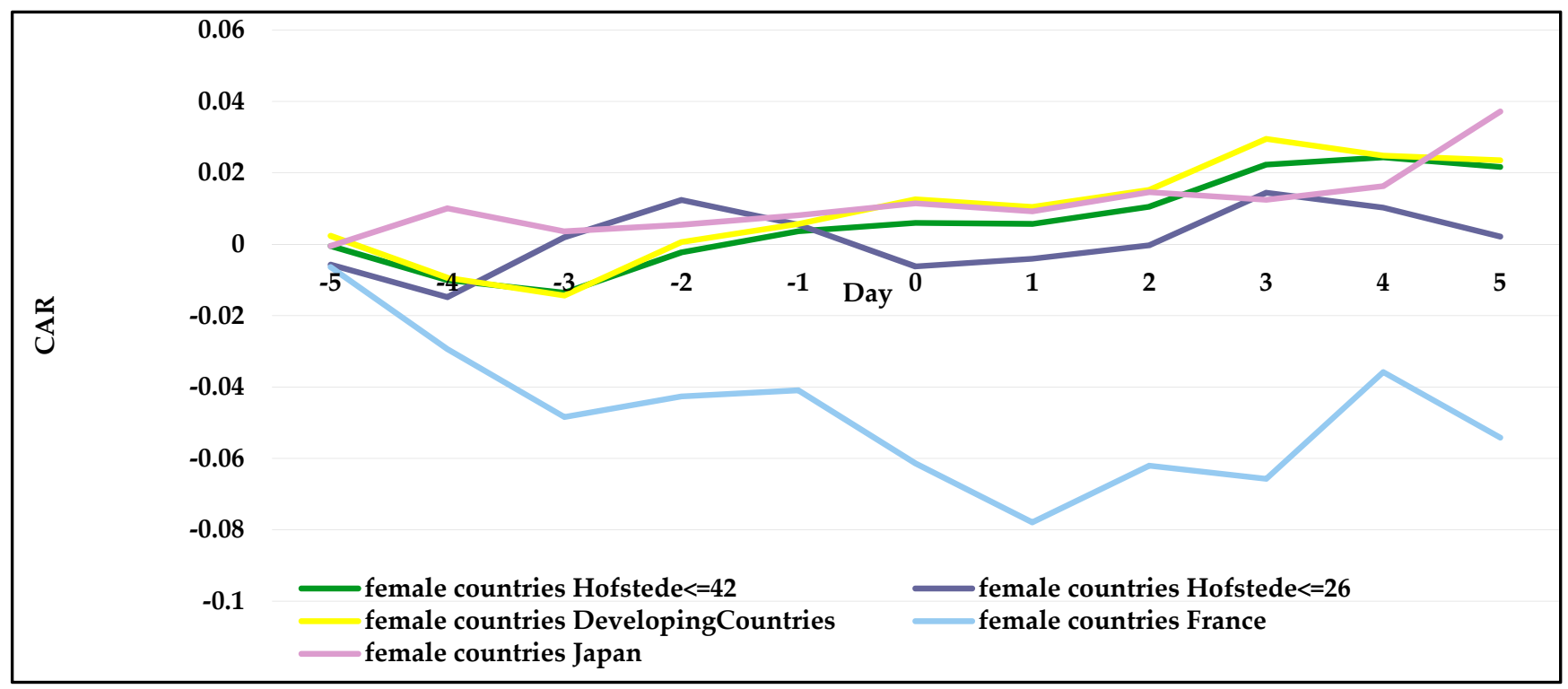

Figure 6. CARs representing the companies on the DJSIs in the sample data $[-1,1]$ to $[-5,5], 2010-2019$.

Figure 6 provides a visual representation of the calculated CARs in this study. French CARs, represented by the blue line, show a negative impact on their market value when appearing on the DJSIs. The green line indicates calculated CARs for the companies in countries with the femininity cultural dimension (masculinity score of $\leq 42$ ). The green line shows that these companies experience positive impacts on their market value within the $[-5,5]$ announcement window. The purple line represents the calculated CARs for companies in the northern European countries with a very low masculinity score $(\leq 26)$. The purple line shows a positive impact on their market value when added to the DJSIs within the $[-5,5]$ announcement window. As discussed before, companies in emerging markets with the femininity cultural dimension also show positive impact on their market value when added to the DJSIs, as represented by the yellow line, similar to the Northern European countries. The results of this study for the Northern European countries are supported by other studies [33] that Scandinavian countries and their companies are at forefront in CSR and sustainability practices.

- To further investigate the results indicated in Figure 6, France was compared with countries having Hofstede's masculinity scores close to 43, but within the femininity cultural dimension, Spain (42) and South Korea (39). In addition, Sweden, with the lowest masculinity score (5), and Japan, with highest masculinity score (92), were included. Figure 7 shows a visualization of this comparison.

In Figure 7, the blue line, representing French companies' CARs, shows a negative impact on market value when appearing on the DJSIs, while companies in Spain (yellow line) and South Korea (green line) show a positive impact on their market value when added to the DJSIs. The same is true for Swedish companies, with Sweden having the lowest masculinity score. Meanwhile, Japanese companies, with Japan having the highest masculinity score, indicate a positive impact on their market value when added to the DJSIs. Figure 7 supports the visualization presented in Figure 6.

- As mentioned before, the interesting finding of the study is that Japanese companies, as indicated by the pinkish line in Figures 6 and 7, show a positive impact on their market value when added to the DJSIs. This is an indication that the Japanese cultural dimension has shifted. Based on research [34], investors need to be more involved and engaged in interactive relationships with firms in order to value and understand their CSR and sustainability strategies. 


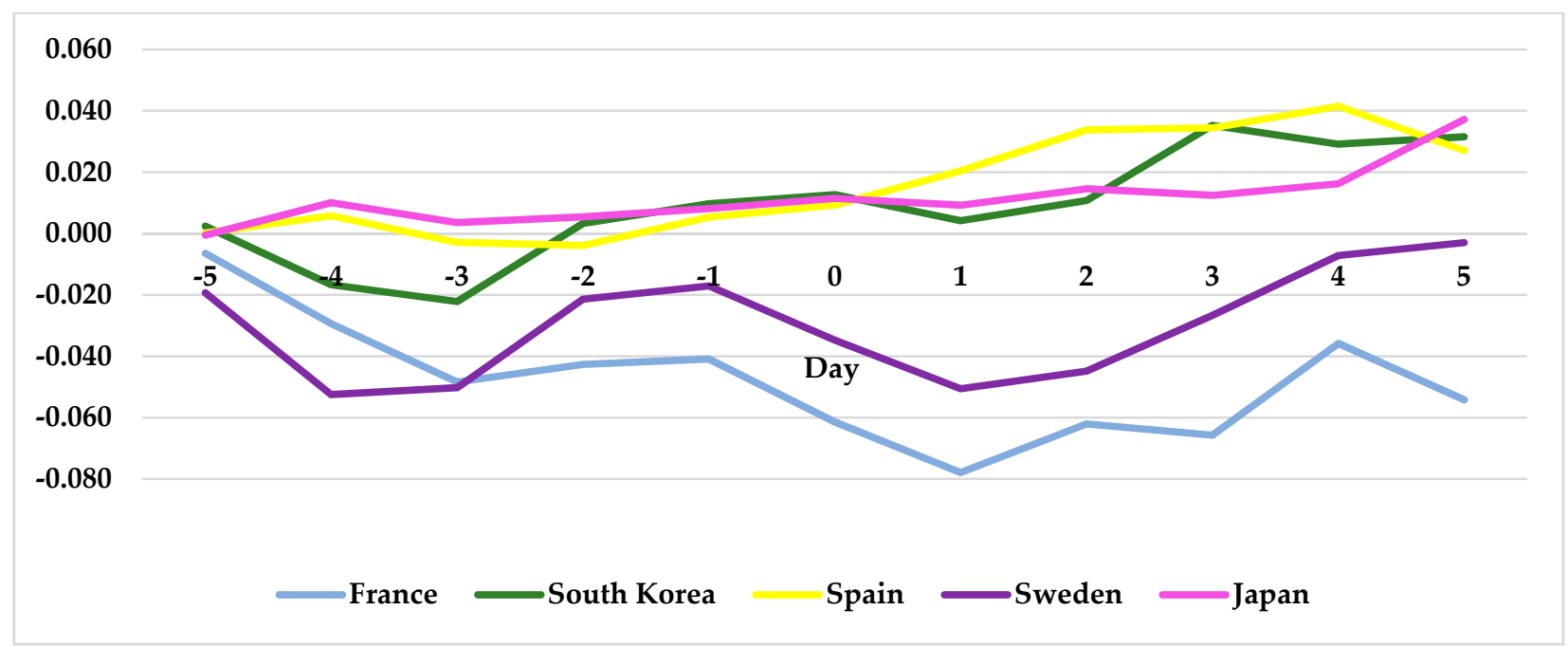

Figure 7. CARs representing the French, Swedish, South Korean, and Japanese companies on the DJSIs in the sample data $[-1,1]$ to $[-5,5], 2010-2019$.

\section{Conclusions}

The global attention to the sustainability practices is evident by UNESCO's sustainability goals [35] and also the Paris Accord, which has been signed by 197 countries to date [23]. These goals emphasize enhancing the health and the welfare of living species, the physical environment, reduction of greenhouse gases (GHG), and the implementation of socially responsible and sustainability strategies across the activity cost chain of companies. As a result, getting the involvement of the companies in implementation of CSR and sustainability strategies is essential to enhancing the quality of life across the globe.

In this study, we selected Hofstede's femininity cultural dimension and explored the notion that countries with a low masculinity cultural dimension care for quality of life more than materialistic wealth. The results of the statistical analyses of this research indicate that countries with the femininity cultural dimension do reward the companies that invest in socially responsible strategies that can enhance the quality of life. These findings support of Hofstede's concept regarding a positive relationship between countries with the femininity cultural dimension and respect for quality of life.

An interesting finding is the impact on the market value of the French companies when they appear on the Dow Jones Sustainability Indices. France, with a Hofstede masculinity score of 43 , is considered to be halfway between the masculinity and femininity cultural dimensions. However, based on our findings, when French companies are added to the DJSIs, their market value is significantly and negatively affected, indicative of a fully masculine cultural dimension. As a result, the concern for materialistic wealth associated with Hofstede's masculinity cultural dimension manifests itself strongly in France. Considering that France is a member of the European Union and that the net-zero carbon emission economy goal is to be achieved by the year 2050 [24], it is interesting that, based on these findings, stockholders do not appreciate the adoption of sustainability strategies by the French companies.

Another interesting finding of this study is the attitude of stockholders of Japanese companies that appear on the DJSI lists. Based on Hofstede's masculinity score, Japan, with the highest masculinity score, should demonstrate more preference for materialistic wealth than quality of life. However, it appears that Japanese stockholders appreciate the adoption of socially responsible strategies by Japanese companies as manifested by the most significant, positive, and prolonged impact on their stock prices among all the studied companies and countries in this research.

Future research in this area can include exploring the cultural changes in different countries, the impact of global agreements on appreciation of CSR and enhancing quality 
of life, and education of stakeholders and the populations of different countries concerning corporate social responsibility and the implementation of sustainability practices by different companies. In addition, we included the highest masculinity cultural dimension country, Japan, in our research and the results of the study indicated cultural change. Future research should include other countries with masculinity cultural dimension to examine any changes in the cultural aspects of such countries.

Author Contributions: Conceptualization: M.T.; methodology: M.T., A.R., L.F., B.S.; software and formal analysis: A.R., M.T., B.S.; investigation: M.T.; resources: M.T., A.R., L.F., B.S.; writing—original draft preparation: M.T.; writing—review and editing: M.T., A.R., L.F., B.S.; visualization: M.T., A.R.; supervision \& project administration: M.T., A.R., L.F. All authors have read and agreed to the published version of the manuscript.

Funding: This research received no external funding.

Institutional Review Board Statement: Not applicable.

Informed Consent Statement: Not applicable.

Data Availability Statement: Not applicable.

Conflicts of Interest: The authors declare no conflict of interest.

\section{References}

1. Hofstede, G. Motivation, leadership, and organization: Do American theories apply abroad? Organ. Dyn. 1980, 9, 42-63. [CrossRef]

2. Hofstede, G. What did GLOBE really measure? Researchers' minds versus respondents' minds. J. Int. Bus. Stud. 2006, 37, 882-896. [CrossRef]

3. Beugelsdijk, S.; Kostova, T.; Roth, K. An overview of Hofstede-inspired country-level culture research in international business since 2006. J. Int. Bus. Stud. 2017, 48, 30-47. [CrossRef]

4. Kim, K.I.; Park, H.-J.; Suzuki, N. Reward allocations in the United States, Japan, and Korea: A comparison of individualistic and collectivistic cultures. Acad. Manag. J. 1990, 33, 188-198.

5. Nelson, M.R.; Brunel, F.F.; Supphellen, M.; Manchanda, R.V. Effects of Culture, Gender, and Moral Obligations on Responses to Charity Advertising Across Masculine and Feminine Cultures. J. Consum. Psychol. 2006, 16, 45-56. [CrossRef]

6. Sørnes, J.-O.; Stephens, K.K.; Sætre, A.S.; Browning, L.D. The reflexivity between ICTs and business culture: Applying Hofstede's theory to compare Norway and the United States. Inf. Sci. J. 2004, 7, 1-30.

7. Venaik, S.; Brewer, P. Avoiding uncertainty in Hofstede and GLOBE. J. Int. Bus. Stud. 2010, 41, 1294-1315. [CrossRef]

8. Brewer, P.; Venaik, S. Individualism-Collectivism in Hofstede and GLOBE. J. Int. Bus. Stud. 2011, 42, 436-445. [CrossRef]

9. Shi, W.; Veenstra, K. The Moderating Effect of Cultural Values on the Relationship between Corporate Social Performance and Firm Performance. J. Bus. Ethics 2021, 174, 89-107. [CrossRef]

10. Ates, S. Membership of sustainability index in an emerging market: Implications for sustainability. J. Clean. Prod. 2020, 250, 119465. [CrossRef]

11. Durand, R.; Paugam, L.; Stolowy, H. Do investors actually value sustainability indices? Replication, development, and new evidence on CSR visibility. Strat. Manag. J. 2019, 40, 1471-1490. [CrossRef]

12. Hawn, O.; Chatterji, A.K.; Mitchell, W. Do investors actually value sustainability? New evidence from investor reactions to the Dow Jones Sustainability Index (DJSI). Strat. Manag. J. 2018, 39, 949-976. [CrossRef]

13. De Santis, P.; Albuquerque, A.; Lizarelli, F. Do sustainable companies have a better financial performance? A study on Brazilian public companies. J. Clean. Prod. 2016, 133, 735-745. [CrossRef]

14. Schmutz, B.; Tehrani, M.; Fulton, L.; Rathgeber, A. Dow Jones Sustainability Indices, Do They Make a Difference? The U.S. and the European Union Companies. Sustainability 2020, 12, 6785. [CrossRef]

15. Zhao, X.; Murrell, A.J. Revisiting the corporate social performance-financial performance link: A replication of Waddock and Graves. Strat. Manag. J. 2016, 37, 2378-2388. [CrossRef]

16. Cheung, A.W.K. Do Stock Investors Value Corporate Sustainability? Evidence from an Event Study. J. Bus. Ethics 2010, 99, 145-165. [CrossRef]

17. Cheung, A.; Wai, K.; Roca, E. The effect on price, liquidity and risk when stocks are added to and deleted from a sustainability index: Evidence from the Asia Pacific context. J. Asian Econ. 2013, 24, 51-65. [CrossRef]

18. Lee, S.; Kim, I.; Hong, C.-H. Who Values Corporate Social Responsibility in the Korean Stock Market? Sustainability 2019, 11, 5924. [CrossRef]

19. Searcy, C.; Elkhawas, D. Corporate sustainability ratings: An investigation into how corporations use the Dow Jones Sustainability Index. J. Clean. Prod. 2012, 35, 79-92. [CrossRef]

20. Hofstede, G. Cultural differences in teaching and learning. Int. J. Intercult. Relat. 1986, 10, 301-320. [CrossRef] 
21. Yilmaz, M.K.; Aksoy, M.; Tatoglu, E. Does the Stock Market Value Inclusion in a Sustainability Index? Evidence from Borsa Istanbul. Sustainability 2020, 12, 483. [CrossRef]

22. Hofstede, G.; Bond, M.H. Hofstede's culture dimensions: An independent validation using Rokeach's value survey. J. Cross-Cult. Psychol. 1984, 15, 417-433. [CrossRef]

23. Climate Focus. The Paris Agreement Summary 2015. 2015. Available online: https://climatefocus.com/sites/default/files/20151 $228 \% 20$ COP\%2021\%20briefing\%20FIN.pdf (accessed on 1 September 2021).

24. 2050 Long-Term Strategy 2020. 2020. Available online: https:/ / ec.europa.eu/clima/policies/strategies/2050_en (accessed on 1 September 2021).

25. Hostede Insights 2021. 2021. Available online: https://www.hofstede-insights.com/product/virtual-certification-in-organisatio nal-culture-2021-1/ (accessed on 1 September 2021).

26. Brown, S.J.; Warner, J.B. Using daily stock returns: The case of event studies. J. Financ. Econ. 1985, 14, 3-31. [CrossRef]

27. Kothari, S.; Warner, J.B. Econometrics of Event Studies**We thank Espen Eckbo, Jon Lewellen, Adam Kolasinski, and Jay Ritter for insightful comments, and Irfan Safdar and Alan Wancier for research assistance. In Handbook of Empirical Corporate Finance; Elsevier BV: Amsterdam, The Netherlands, 2007; pp. 3-36.

28. Kothari, S.P.; Warner, J.B. The Econometrics of Event Studies. 2006. Available online: https://www.bu.edu/econ/files/2011/01 /KothariWarner2.pdf (accessed on 1 September 2021).

29. MacKinlay, A.C. Event studies in economics and finance. J. Econ. Lit. 1997, 35, 13-39.

30. Chan, W.S. Stock price reaction to news and no-news: Drift and reversal after headlines. J. Financ. Econ. 2003, 70, 223-260. [CrossRef]

31. Brown, S.; Warner, J.B. Measuring security price performance. J. Financ. Econ. 1980, 8, 205-258. [CrossRef]

32. Campbell, J.Y.; Lo, A.W.; MacKinlay, A.C. Event-Study Analysis, The Econometrics of Financial Markets; Princeton University Press: Princeton, NJ, USA, 1997.

33. Strand, R.; Freeman, R.E.; Hockerts, K. Corporate social responsibility and sustainability in Scandinavia: An overview. J. Bus. Ethics 2015, 127, 1-15. [CrossRef]

34. Hockerts, K.; Moir, K. Communicating corporate responsibility to investors: The changing role of the investor relations function. J. Bus. Ethics 2004, 52, 85-98. [CrossRef]

35. UNESCO. UNESCO and Sustainable Development Goals 2019. 2019. Available online: https://en.unesco.org/sustainabledevel opmentgoals (accessed on 1 September 2021). 